\title{
Creating content for the WWW
}

\author{
F.H.B. Serfontein \\ Departement of Economics, University of South Africa \\ Serfofhb@alpha.unisa.ac.za
}

\section{Contents}

Introduction

What means

Means available

Barriers to Web-based teaching

What are the benefits, if any?

Using JavaScript

Brigham Young project

Conclusion

Bibliography

\section{Introduction}

Although the WWW (World-Wide Web) has the potential to enrich and enhance the learning experience for residential and correspondence students, this potential has not been fully exploited. While many reasons exist for this underutilisation, an important factor is that lecturers are currently unable for various reasons to create content for the WWW.

In the first part of the paper attention is paid to what the process of creating content (teaching material) for a WWW course, aimed at a large number of correspondence students, entails and what the requirements are that need to be met in order to empower lecturers to create this content. Current barriers to the successful creation of content for such a course are also identified.

In the second part of the paper, I demonstrate how JavaScript, a tool available on the WWW, can be used to create moderately interactive content for both 'on-line' and 'off-line' students. I will also show and comment on the project jointly run by the Department of Economics of Unisa and the University of Brigham Young (Utah, USA) in using the WWW to teach a large number of first-year students.

\section{What means?}


The World-Wide Web (WWW) provides lecturers with additional and alternative means to teach and evaluate students. The content that needs to be created and the way in which it is done will depend on the means that are going to be used. And this will largely depend on whether the WWW is viewed as complementary to the existing course or as an alternative way of teaching and evaluating students.

If the WWW is viewed as complementary to an existing course, the lecturer is facing the challenge of finding available, appropriate means to enhance his or her course. The means provided by the WWW are then viewed as additional instruments that need to be integrated into the existing course. The current content of a course and the existing mode of teaching will have a decisive influence on what means are chosen. Due to differences in content, the means chosen by an Economics History lecturer, for example, will differ from those employed by an Economics 1 lecturer.

To choose the most appropriate means lecturers must not only be subject specialists and experts in the current mode of teaching, but must also be familiar with the uses and abuses of the different instruments provided by the WWW.

The feasibility of using these instruments, however, will depend on such factors as student numbers, access to the WWW, institutional support, the technical expertise of lecturers, time considerations and cost implications. The instruments that will eventually be used, might not necessarily be the best there are.

Once a lecturer knows what means are going to be used the process of content creation can start in earnest.

It must be kept in mind that means influence content. Current content is to a large extent a function of past practices and wisdom and it is to be expected that as the means change so will the content. For example content previously considered to be impossible to teach or evaluate through a correspondence course might turn out to be feasible through some of the means provided by the WWW.

In developing a Web-based course for Economics 1 distance-education students, it was decided to use as many instruments as possible, as well as the present course as a point of departure. It is through this process that we hope to find answers concerning the suitability and feasibility of the different means, and to establish what is required of lecturers in terms of technical expertise and content creation to be successful.

\section{Means available}

The means provided by the WWW for which content must be created can be broadly summarised by looking at the following components of online teaching. To use the components in the grey area (light blue on the screen), access to the WWW is required while an ordinary computer will be sufficient for the rest of the components.

Figure 1 


\section{Components of online teaching}

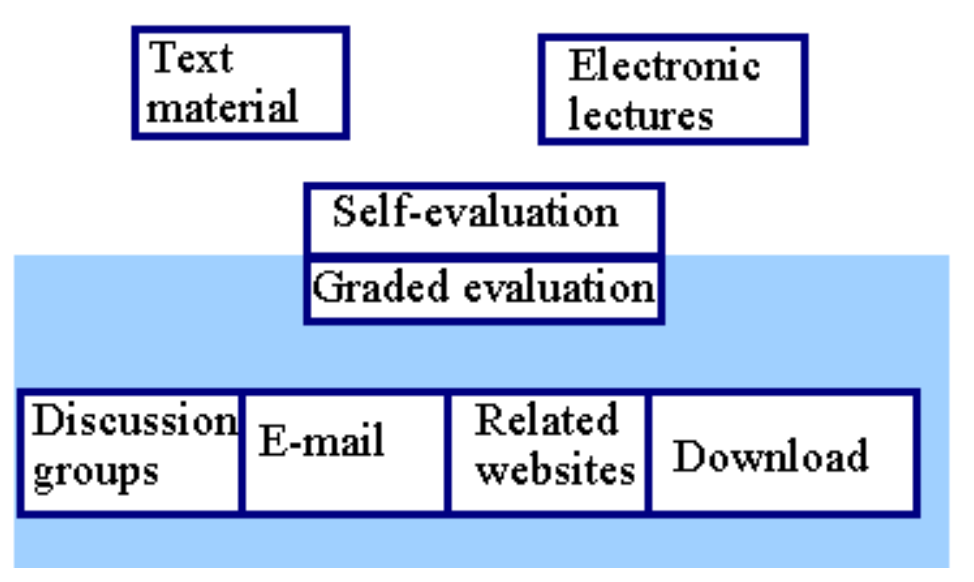

Text material: One of the first things that is done when a correspondence course is converted to a Web-based course is the conversion of existing text material into a compatible format (preferably HTML) for the WWW. This includes things like information about administrative aspects and study material such as an electronic text book, study guides, articles and notes. This is also referred to as text dumping and does not necessarily imply online or Web-based teaching. However, there are certain benefits that make it a worthwhile project.

The WWW does provide a fast, cost-effective and reliable way of delivering text material, and for many distance-teaching students receiving study material on time would be a major improvement over the current delivery system. The same material developed for the WWW can also be delivered via CD-ROM or disks, thereby increasing the delivery options.

If the lecturer is part of the process of converting his or her study material, and is expected to maintain and improve on it, the next easy step to take is to start using features such as hyperlinks, other text enhancing features and interactivity. Text created for the Web can also be changed and updated very easily, thereby providing more flexibility than is the current case for correspondence courses.

Electronic lectures: Electronic lectures are characterised by high levels of interactivity and the use of various multimedia features to various degrees in order to teach and enrich the study material for the student.

The creation of this material is very time consuming and requires specialised skills. Various options exist for the creation of these electronic lectures, and the challenge is to get hold of a set of tools that enable a lecturer to create these interactive lectures by means of his/her desktop computer.

The creation of a database consisting of interactive teaching material and software that can be customised by the lecturers will help to speed up this process. The creation of such a database is a major undertaking which is beyond the reach of many institutions, and consideration should be given to the creation of a shared database between institutions in subjects where there is a high degree of similarity in content.

Evaluation: The WWW provides a variety of ways in which students can be evaluated, but careful planning will be the key to success. The evaluation process can be based on selfevaluation by the student and/or graded evaluation both by computer and by the lecturer. It can take the form of true-or-false questions; multiple-choice questions; case studies; written assignments (both paragraph or essay-type questions); and contributions to discussion 
groups.

The course content and the means used to teach the course will to a great extent determine how students are evaluated. The evaluation of students can take place at a particular time and place determined by the department and the University, or it can be at the discretion of the students, thereby providing more flexibility.

The evaluation currently used in the Web-based course for Economics 1 is on par with that used in the correspondence course. When evaluating students taking the correspondence course certain constraints relating to time, space and institutional support had to be taken into account, and they largely determine how students are evaluated. The operative principle is self-evaluation by means of true-or-false questions, multiple-choice questions and short questions. Admission to the examination is automatic, and examination takes place at a particular time and place.

By using the WWW many of these constraints disappear - in the future it will be possible to have a system of graded evaluation by the lecturer and/or server and for examinations to take place at times better suited for both the students and the lecturers. This, however, requires the development of Web-based courses that are independent of the existing correspondence course.

E-mail and discussion groups: This is one of the more popular and successful features of online teaching, and many online courses consist of only these two features. It is easy to set up, and little specialised knowledge is required. It seems to work well if student numbers are small, contributions to the discussion group are part of the evaluation, and the lecturer is an active participant. For distance education students it adds the benefit that it decreases the feeling of isolation by providing student-to-student and student-to-lecturer communication.

For a distance teaching lecturer with thousands of students this can be a potential catastrophe and there is a high level of resistance among these lecturers. To overcome some of the problems, e-mail inquiries can be divided into the following three categories:

- administrative inquiries which deal with things such as examination admissions, dates and venues, registration procedures, fees and delivery of study material;

- content-related inquiries which deal with the academic content of the course; and

- technical inquiries dealing with issues such as the software and hardware.

Before a student sends an e-mail inquiry, he or she selects the appropriate category, reads through the frequently asked questions page and then, if still necessary, sends the message. For each category a unique e-mail address is created where the message is received, opened and answered by the department concerned (administrative, academic or technical support). There is no need to give the lecturer's e-mail address, and a buffer can be created to shield the lecturer from being flooded with e-mail inquiries.

To make learning possible through discussion groups when faced with a large number of students the following is envisaged. Two kinds of discussion groups, namely, informal and formal groups, are created. The informal discussion group is unmoderated and the students may choose the topics of discussion. The formal discussion group concentrates on the content of the course and the lecturer is an active participant. The group is only active for a specified time and deals with a specific topic that is regarded as suitable for this medium. Participation is voluntary but the number of participants is limited while the rest have 'observer status'. Once the discussion group adjourns, the information is archived and made available to students to browse through. 
Related Web sites: The content of correspondence courses depends to a large extent on the prescribed textbook. The use of additional and recommended study material is limited due to problems of making this material available to thousands of students who are geographically dispersed. Not only is this limitation lifted, provided that copyright is respected by the use of related Web sites, but it is also possible, not necessarily preferable, to develop a course of which large parts are based on material from related Web sites. With the necessary permission and technical skills these related Web sites can be customised, changed and integrated in a course. This will significantly decrease the time spent on developing teaching material and may even give international credibility to a course.

Active learning experiences that directly involve the students can be created with up-to-date information and news about specific events available on the WWW. Finding and contextualising these materials are time-consuming operations and much scope for collaboration between lecturers at various institutions exists to make this a reality.

Download: By using the download function, relevant and updated information can be made available to students on a continuous basis while lecturers have the opportunity of constantly improving and developing their courses. It would also be possible for former students to stay in touch with new developments in the subject field, and a contribution will be made to lifelong learning.

\section{Barriers to Web-based teaching}

Lecturers at distance teaching institutions have acquired over many years through trial and error a set of skills that is appropriate for the development and delivery of correspondencebased courses. They do it with a sense of competence and confidence and they know which pitfalls to avoid. While many similarities exist between the creation of paper-based and Webbased courses the latter presents a new teaching medium with its own peculiar and unique challenges, challenges that can only be met with a new set of skills, new ways of thinking and a certain amount of risk taking.

No blueprint or set of instructions exists that can guarantee success. The absence of tried and tested methods in a faculty or department increases the probability of failure. And failure, given the present conditions of financial constraints, increased competiton, declining student numbers, the threat of retrenchments, affirmative action, internal strife, etc., is one thing that lecturers and their distance teaching institutions try to avoid at all cost.

This is the dilemma facing lecturers and traditional distance teaching institutions: Do you stick with what you are good at and wait for others to solve the problems of online teaching and then enter the market or do you commit yourself and your resources to something whose probability of success is very uncertain? The higher this level of uncertainty, the less likely lecturers and institutions will be to commit themselves to obtaining the skills and expertise necessary for Web-based teaching. While a variety of factors contribute to this uncertainty, in my opinion the following factors - from a lecturer's perspective - are most important.

Top

\section{What are the benefits, if any?}

While everyone agrees that Web-based teaching cannot be ignored, mainly because our competitors are using it, a frequently asked question is: What are the benefits of Web-based 
teaching for students and lecturers? This is not an easy question to answer, given that many of the benefits as mentioned earlier are already incorporated in correspondence courses. Immediate feedback can be provided by way of self-assesment assignments, and the lecturer is just a phone call away. Through Web technology the learning experience of students can be enhanced and different teaching strategies can be followed, but ultimately the question that needs to be answered is whether it will increase the pass rate. Only, time and experience will tell.

Lecturers will have to learn new skills and adapt to changing teaching practices while the underlying fear of failure, of being replaced by a computer, and of an increase in workload are a major drawbacks. Special motivational benefits will have to be implemented in an effort to change lecturers' attitudes concerning these new teaching skills and opportunities.

Promotion and mobility: Promotion at universities, as well as mobility between universities, depends mainly on two things: qualifications and research record (publish or perish). A lecturer interested in moving through the ranks will be well advised to concentrate on these two areas which will undoubtedly take up most of his or her time and effort. These are important requirements and should remain part of the culture of our academic institutions, but incentives must be created to convince lecturers to pursue with the same dedication and vigour the challenges of online teaching. Providing incentives is also a way of indicating the relative importance that is attached to online teaching.

Access and cost considerations: A frequently used and strong argument against the use of Web-based teaching at traditional distance teaching institutions is that the majority of registered and potential students do not have access to the Internet. It is therefore, according to said argument, a waste of time to develop a product that will never be available to the majority of students, and is likely to remain available to only a small privileged minority. It would be helpful and a great motivational force if some national attempt can be made to ensure low cost access to the WWW for South Africans.

Institutional support: The golden rule is not to attempt Web-based teaching without institutional support. Ample evidence exists on the WWW of failed attempts by lecturers trying to strike out on their own.

Trying to implement online teaching while the institution is geared for a different mode of delivery means you have to rely on the goodwill of people to help and accommodate you. Overcoming managerial and administrative barriers can be very distractive, time consuming and demotivational.

Institutional support implies more than just technical assistance and training and should also include appropriate management policies and practices.

Workload: To use the WWW successfully and to create the required content are going to demand more time and effort from lecturers: time to spend on acquiring an understanding of the new medium, and effort to learn new skills and creating content. Given the decline in staff numbers and that the prevailing course will not be replaced by a Web-based course, the workload of lecturers will increase significantly. Unless ways and means can be found to provide time for Web-based teaching, it will be characterised by sporadic, interrupted attempts at using the medium without the satisfaction of a job well done.

\section{Using JavaScript}


There are many powerful software packages available on the market for the creation of interactive multimedia lectures. These products are usually expensive and extensive, and their use requires specialised skills. JavaScript is not as powerful as some of these products but in my view offers some definite advantages for lecturers in creating content for the WWW and for computer-assisted teaching.

Some of the benefits of JavaScript are:

- It is free of charge and numerous examples of how it can be used are available on the WWW. It is moderately easy to customise these examples once some basic principles are mastered and electronic lectures with different degrees of feedback, interactivity and multimedia features can be created by the lecturer.

- It requires relatively small processor power and bandwidth

- It is not too difficult to master and very little knowledge of programming is required.

- It can be delivered via the WWW, CD-ROM and disks and students do not have to be connected to the WWW to benefit from it.

- Content once created can easily be changed by the lecturer. This provides the lecturer with a powerful tool to make corrections, update information and add new features.

The example of the usage of JavaScript that I will demonstrate was created with some basic JavaScript tools that I picked up from the WWW. Unlike the Brigham Young site, which I will demonstrate after this, I did not make use of any professional assistance which I believe will improve on this attempt. The idea was to create something with the means available to me.

\section{Brigham Young project}

After viewing our course materials and taking our student numbers into account, the University of Brigham Young situated in Provo, Utah has offered to use the Economics 1 course for a pilot project to determine the feasibility of providing teaching via the WWW to a large number of students.

The project started in April this year. Brigham Young provided the technical expertise and we the content, which includes some input regarding the design and features of the Web site. It was decided to use as many features as possible and all the components of online teaching listed in Ffiigure 1 are present on the Web site. Whether we will be able to use all these means successfully must still be determined.

The first phase of the project consisted in converting the existing study material to a suitable format and structure. The second phase was to provide some form of evaluation and feedback to the student. This was achieved through true-or-false questions, multiple-choice and short questions with immediate feedback. The third phase involves the use of discussion groups and e-mail facilities. The fourth and most difficult phase, which must still be implemented, is to provide interactive electronic lectures for the students.

\section{Conclusion}

National, institutional and individual effort will be required if the full potential provided by the WWW to teach a large number of students is to be tapped. 
At national level affordable accessibility to the WWW for South African students need to be provided. On an institutional level an environment conducive to the creation of teaching material and delivery thereof must be put in place by providing administrative and technical support and motivational incentives for lecturers. Lecturers will have to put in some effort as well by taking the time to understand how means available from the WWW can be used and how content for these means can be created. To this end they will have to learn new skills and an innovative way of thinking about their role as teachers.

\section{Bibliography}

McCain, R.S. 1999. Developing an on-line textbook: Question-led teaching and the World Wide Web. Journal of Economic Education, 30 (Summer): 248-260.

McLendon, E. and Cronk, P. Rethinking academic management practices: A case of meeting new challenges in on-line delivery. Available online at.

Sherry, L. 1996. Issues is distance learning. International Journal of Educational Telecommunications, 1 (4): 337-365.

Simkins, P.S. 1999. Promoting active-student learning using the World Wide Web in Economics courses. Journal of Economic Education, 30 (Summer): 278-287.

\section{Disclaimer}

Articles published in SAJIM are the opinions of the authors and do not necessarily reflect the opinion of the Editor, Board, Publisher, Webmaster or the Rand Afrikaans University. The user hereby waives any claim he/she/they may have or acquire against the publisher, its suppliers, licensees and sub licensees and indemnifies all said persons from any claims, lawsuits, proceedings, costs, special, incidental, consequential or indirect damages, including damages for loss of profits, loss of business or downtime arising out of or relating to the user's use of the Website. 
ISSN 1560-683X

Published by InterWord Communications for the Centre for Research in Web-based Applications, Rand Afrikaans University 